\title{
3D Geological Modeling in Mineral Deposits (Copper Ore Body Cases)
}

\author{
Sirelda Bele, (PhD candidate) \\ Albanian Geological Survey, Albania
}

Doi: 10.19044/esj.2018.v14n15p1 URL:http://dx.doi.org/10.19044/esj.2018.v14n15p1

\begin{abstract}
Munella's deposit is one of the most important mineral deposits of Albania. It is rich in mineral resources such as copper, zinc, gold, etc. For this reason Geological 3D modeling is very important because it gives detailed information on management in the most optimal way to mine. In this article, 3D modeling of copper bodies was carried out through modeling software using the implicit method. This method uses advanced algorithms that are Polyharmonic Radial Basis Functions (RBF) generates the best surface area of the ore that can have some $\mathrm{Z}$ values and can perfectly customize the incomplete surfaces by utilizing 211 drilling data. The ore bodies that are created with this method are divided into blocks that represent the distribution of copper in $\%$. The results achieved in this study provide an accurate overview of the most important sources of deposits and major concentrations of copper for the efficient management and exploitation of the mine.
\end{abstract}

Keywords: 3D Modeling, Block Modellig, Implicit method, Drillholes, Deposit

\section{Introduction}

To better understand and interpret this study, we need to identify the problem and the importance of finding a solution.

With the recent development and the general acceptance of information technology, the number of software's in geological and mineral applications has intensely developed. With the development of some major mining activities in the world, the valuation of reserves and mining planning has been done through the computer for over 20 years. These activities have developed programs that are specific to them. However, this trend brought about changes in the method and working procedure, but has in particular imposed a very important challenge and an opportunity for mining professionals. For mining applications, as in other areas, where economic criteria require the continuous availability of software applications depending 
entirely on the workplace, a better solution is that of the integrated system. Nowadays 3DGM can integrate 2D GIS data, database, statistical analysis and $3 \mathrm{D}$ visual technology by developing $3 \mathrm{D}$ visualization modeling software

Description of the study area

\section{Location and geographic position}

The Munella deposit is located in the district of Puka about $30 \mathrm{~km}$ southeast of the town of Fushë Arrëz in Albania Northen.

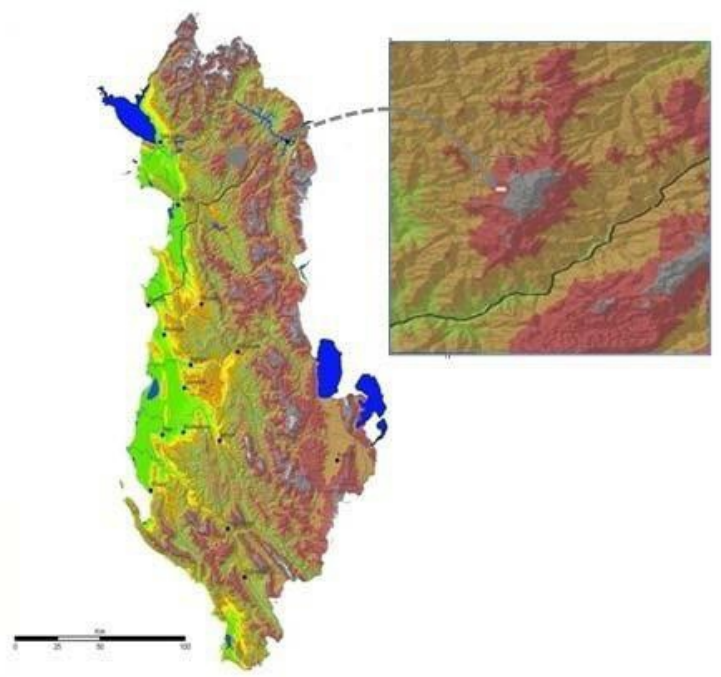

Figure 1. Location of the Munella deposit

\section{The geological settings}

By the geological point of view, the polymetallic deposit of Munella, two volcanic rock types are present. They are well distinguished in micro and macroscopically from each other and are represented by the upper bed package and the sub-package Munella spilite (calcibasalt - andesite) with their types which are generally placed in the upper levels and sub bed-package of Qaf Bari. The rocks that set up Munella's deposit, within which mineral areas and minerals bodies of copper and zinc can be found, are:
Basalt andesite,
- Andesite - basalt
Dacite - rhyolite.

\section{Economic Minerals}

In the polymetallic deposit of Munella, there are some economic minerals - such as:

Sulphide mineralization of copper, zinc, iron located in volcanic rocks, mineralization of manganese (oxides) in the package friable clay, volcanic glass in the volcanic rocks, coal in terrigenous rocks of the Cretaceous and construction materials from the Cretaceous carbonates. 


\section{Methodology and data}

3D geological modeling allows for the creation of complex geological models and geological objects in the 3D environment using geological maps, geological analysis records, structural information, geophysical and geochemical data (Mallet, 2002; Zanchi et al., 2009). 3D geological modeling can be applied to set up 3D structural patterns, rocks, geophysical anomalies, geochemical anomalies, and mineral bodies or any spatial three-dimensional information. It should be understood that every point in space has $\mathrm{X}, \mathrm{Y}, \mathrm{Z}$ and one or more other attributes referring to this space point.

3D geological modeling is very important and is used widely by researchers, mining exploration companies, geological institutions, etc. This methodology has been developing in our contry in recent years. For geologists this is a great help in terms of:

- Mining Management

- Calculation of reserves

- Less time spent on modeling

In this case study the geological maps at scale 1:2000 are used in order to retrieve the general information for geology in area of interest. (Archives of the Albanian Geological Survey).

Cross-sectional and drill hole adds the third dimension in order to give a more detailed interpretation of underground structures. However, if we have available detailed information, we will be able to do a better interpretation of the structure or intrusive rocks. This should take under consideration all data such as (R.Kamberaj), geological columns which are built from geological surveys conducted over the years, geological map of the Munella deposit scale 1: 2000 (Deda. T), the layout of the mine workings, 19 profiles (longitudinal, structural), tables and graphs.

Geological profiles, i.e. geological columns with drilling numbers, coordinates $(\mathrm{x}, \mathrm{y}, \mathrm{z})$ of drilling, direction azimuth, the angle of decline, depth, information on rock formations. In total, there were 225 drillings. Chemical analyzes, topographic, geochemical data have been processed and standardized in the same 3D coordinate system (Gauss Kruger, Pulcovo 1942 Zone 4 ). The type of data integrated within a 3-D model depends on data availability, density, and distribution, as well as project objectives and working scale (Fallara, F., 2006). Through combining contact limits with geological and geophysical information orientation, we can build geological models. For this we need the use of 3D modeling software.

For the realization of the methodology it was deemed reasonable to intertwine the mapping programs and the special modeling programs by making an interconection with the data of the area under study.

In order to setup a model of 3D mineral bodies accurately from geological data (geologic maps with varying degrees, cross section and drill 
hole), it is necessary to develop a methodology that takes into account geological data

There are three steps we need to follow in order to arrive at 3D Modeling and block -modeling:

- $\quad$ Creating and Compilation of database

- $\quad$ Building Wire framing

- $\quad$ Creating the Block Model

\section{Discussion and conclusion}

\section{Creating the database}

The database is built from gathering, registration, verification and data processing that form the basis for mineral resource evaluation.

Traditional data storage techniques have changed over time, as a result data may have been lost or the material may have been of poor quality, there may be duplication of information; therefore it is necessary to filter the data collected. For this reason it is necessary to verify all the collected data.

\section{Tables}

Table 1. Coordinates

Presentation of $\mathrm{X}, \mathrm{Y}, \mathrm{Z}$ coordinates and the depth of drilling.

\begin{tabular}{|ccccccc|}
\hline Dholes & X & Y & RL & TDepth & Dip & Azimuth \\
\hline 3 & 4424115.05 & 4649365.93 & 1218.78 & 249.15 & -85 & 55 \\
\hline 4 & 4424139.81 & 4649314 & 1124.68 & 116.3 & -65 & 55 \\
\hline 5 & 4424139.81 & 4649314 & 1124.18 & 304.4 & -89 & 55 \\
\hline 6 & 4424157.2 & 4649342.56 & 1230.26 & 139.4 & -76 & 55 \\
\hline 7 & 4424010.91 & 4649548.36 & 1208.94 & 123 & -85 & 55 \\
\hline
\end{tabular}

Table 2. Lithology

Presentation of coordinates, depth of drilling, lithology.

\begin{tabular}{|cccccc|} 
Dhole & Sample_id & From & To & Lithcodee & Alteration \\
\hline 3 & 3 & 106 & 249.15 & MZ & \\
\hline 4 & 1 & 0 & 73.9 & AN & \\
\hline 4 & 2 & 73.9 & 116.3 & RD & Chlorizitation \\
\hline 5 & 1 & 0 & 121.5 & AN & \\
\hline
\end{tabular}

Table 3. Survey

The table shows the X, Y, Z, coordinates azimuth, zenith angle. Depth of the drilling is with the average drop angle -81 . The maximum depth reaches $560 \mathrm{~m}$.

\begin{tabular}{|ccccccc|} 
Dholes & Sample_idd & X & Y & Depth & Dip & Azimuth \\
3 & 1 & 4424115.05 & 4649365.93 & 0 & -85 & 55 \\
\hline
\end{tabular}




\begin{tabular}{|llccccc|}
\hline 4 & 1 & 4424139.81 & 4649314 & 0 & -65 & 55 \\
\hline 6 & 1 & 4424157.2 & 4649342.56 & 0 & -76 & 55 \\
\hline 7 & 1 & 4424010.91 & 4649548.36 & 0 & -85 & 55 \\
\hline 8 & 1 & 4424017.54 & 4649488.14 & 0 & -80 & 55 \\
\hline
\end{tabular}

Table 4. Analysis

The analysis table presents the data of the results of the analysis, it considers the number of drillings, depth, and content in\% of elements such as $\mathrm{Cu}, \mathrm{S}, \mathrm{Co}, \mathrm{Zn}$ etc.

\begin{tabular}{|cccccccc|}
\hline Dholes & Sampled_id & From & To & Thickness & $\mathrm{Cu}$ & $\mathrm{Co}$ & $\mathrm{Zn}$ \\
\hline 83 & 4 & 132.4 & 133.5 & 1.10 & & 0.025 & 1.41 \\
\hline 84 & 1 & 180 & 181 & 1.00 & 0.35 & 0.0025 & \\
\hline 84 & 2 & 186.3 & 186.9 & 0.60 & 0.27 & 0.0012 & \\
\hline 84 & 3 & 186.9 & 187.5 & 0.60 & 0.91 & 0.0012 & \\
\hline 84 & 4 & 187.8 & 188.8 & 1.00 & 0.37 & 0.0012 & \\
\hline
\end{tabular}

Once the tables are built, they are also imported from the 3D modeling program. After importing the database into the modeling program, data control is performed. Control is a very important process because it can eliminate the incorrect values in the table and to improve data consistency.

\section{Classic statistics}

Once we have collected and controlled the data, we start over the statistical analysis by also creating the database of the interpretative data. This process is referred to as analysis of research data or classical analysis.

\section{Histogram}

Histogram is another way to present the distribution of evidence value data. The normal distribution of $\mathrm{Cu} \log$ in the Munella deposit.

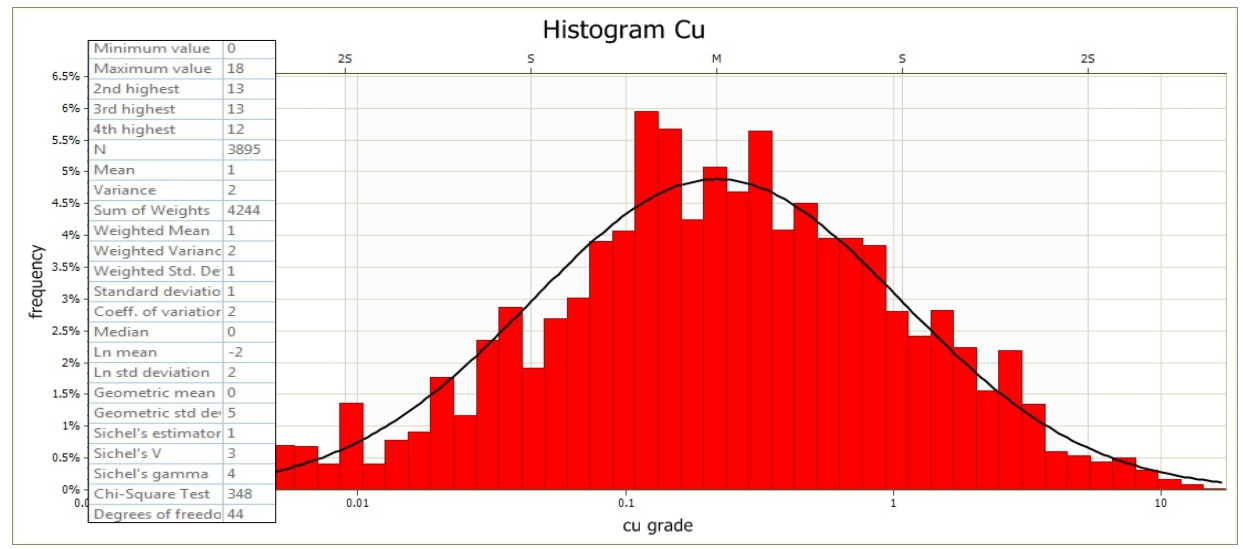

Figure 2 Histogram 
Reading the histogram we have the maximum value and minimum value, average, variance, number of evidence involved, etc. The total number of samples is 3895 , minimum value 0 and maximum value 18 , Coeff.of variation 2 , variance 2 , standard deviation 2 , mean 1 , etc.

\section{Cumulative Frequency}

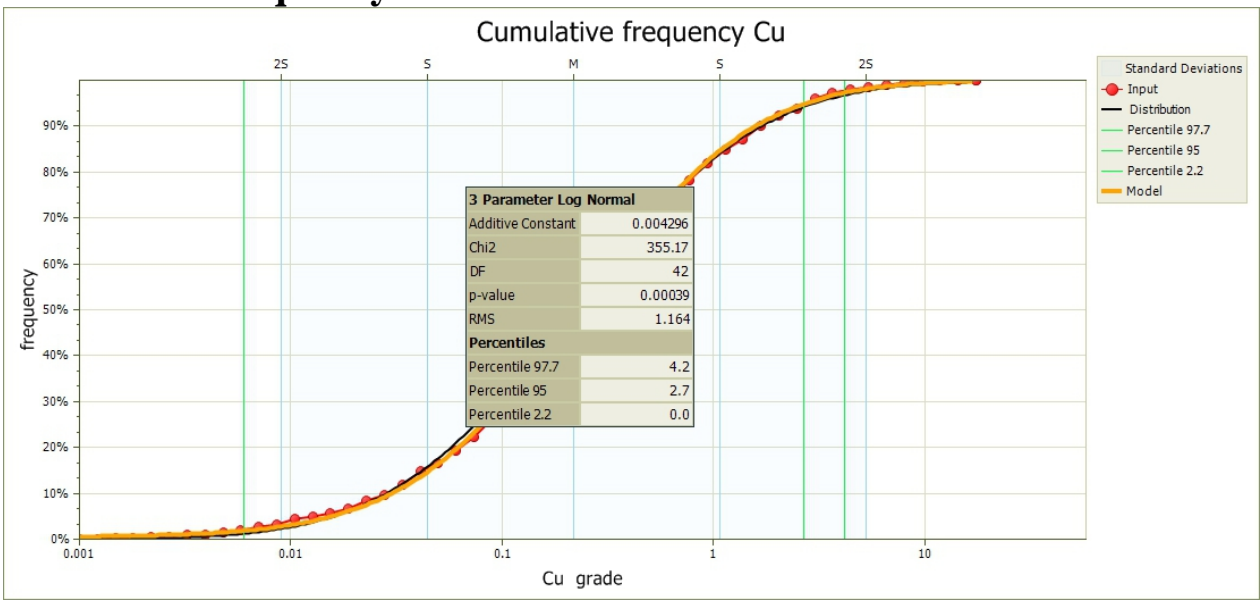

Figure 3 Cumulative Frequency

Determining the upper limit of the balancing cut or upper limit (the boundary where any value greater than the balancing cut is called an utlier and is taken into account in calculations as data of equal value to the upper bound that is also called the threshold. This limit corresponds to +2 sigma or $97.7 \%$. The same should be done for the lower limit or -2 sigma.

\section{Results by the Wireframing}

The purpose of the interpretation and Wireframing is to divide the domains in the source and provide each of them with their own wireframe from the geological, spatial and statistical point of view. It should be said that a domain may consist of one or several wireframes with condition that these wireframes represent a geological, statistical and spatial environment. 3D coordinates of the entire source are determined through sample intervals and the data are used to interpret and perform Wireframing. 
Copper ore bodies built by implicit method

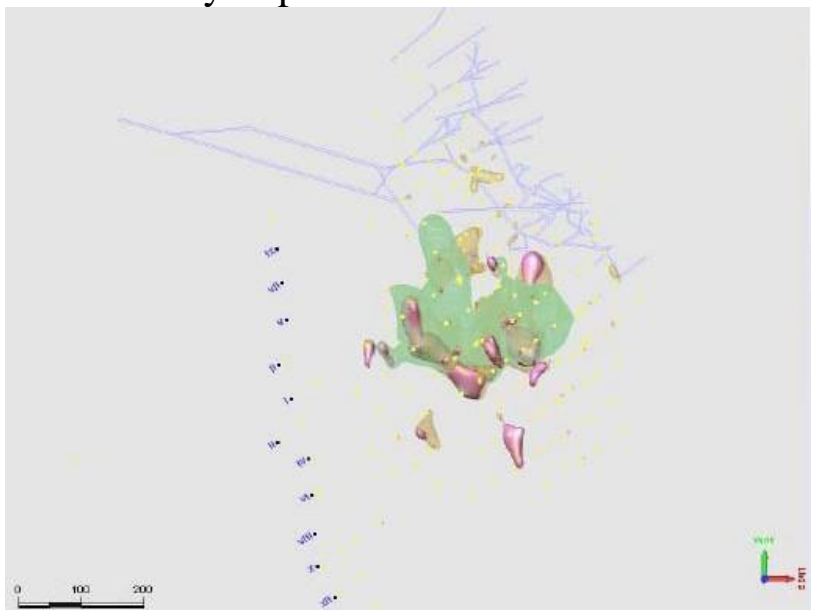

Figure 4. Ore bodies, galleries, profiles built by implicit method

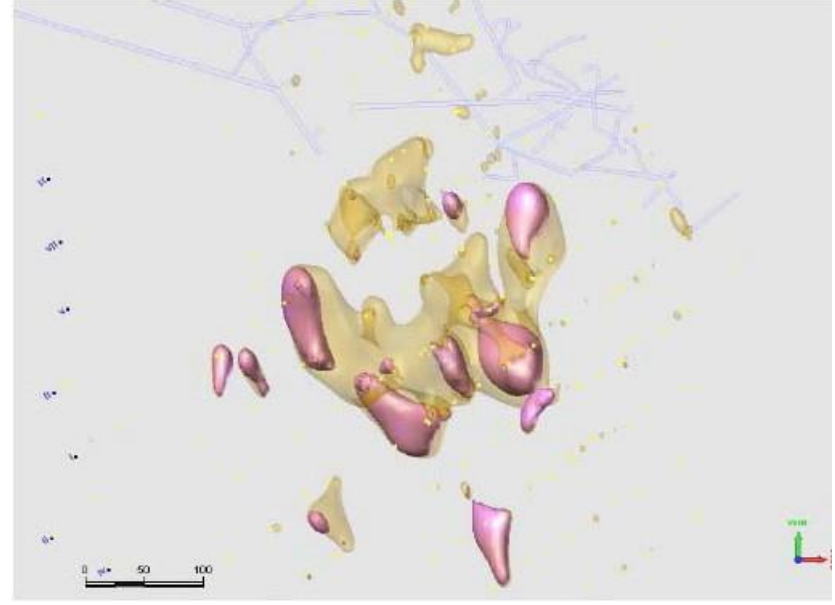

Figure 5. Presentation of copper bodies

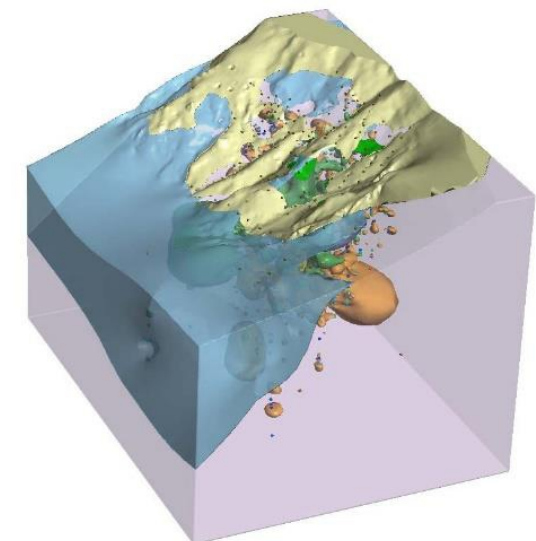

Figure 6. The 3D geological model together with the ore bodies of the deposit seen from above 


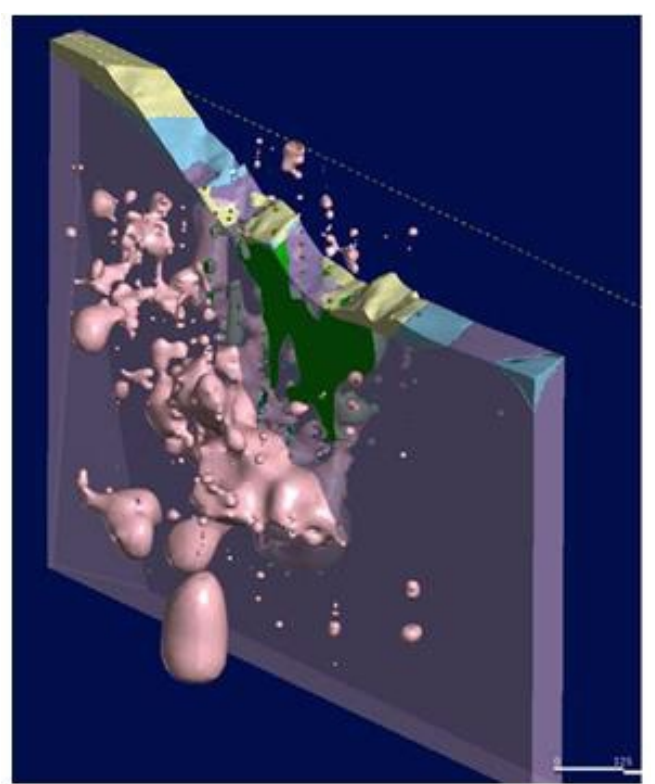

Figure 7. It shows mineral area and a part of the geological model

\section{Creating a block model}

The model should be large enough to cover the full range of input data, which in most cases consist of one or more wireframes and drilling databases. To determine the extent of a block-model, set the minimum coordinates of the starting blocks - the lowest angle, the south-west of the model, and the maximum block coordinates - the highest angle to the north-east of the model. This established space is the total area of impact that will be used for estimating the reserves. The sub-cells are not only helpful for accurate construction of a 3D grade model for the ore body, but also for identification of continuous sensitive differences of $\mathrm{Cu}$-grade in a single ore body (Wang, G., Chen, J., Du, Y., 2007).

To select the size of the block model, we should also consider several factors, such as:

- $\quad$ The size of the blocks depend on the characteristics of the source

- $\quad$ The size of the forms of bodies

- Type of ore

- Zonality,

- $\quad$ Length of sample analysis

Based on the cross section view of the geometric shape of the bodies (such as width and height), after some tests, I selected the dimensions of the blocks: $2 \mathrm{~m} * 2 \mathrm{~m} * 1 \mathrm{~m}$ as the most suitable size, these dimensions best fit the space of the bodies. 


\section{Selecting the modeling method}

Selection of the modeling method, insertion of layers and statistical complexity can help identify the best approach for the area under study. For this we rely on the tables and classification systems of ore reserves (Annels, A.E.1991). First important point is if the geometry is simple or complex, copper in our case can be classified as simple geometry. (From the statistical table for copper, type $\mathrm{A} 2, \mathrm{COV}=1.906$ ).

The true value of mineral resources is not known until the shape, size and other characteristics are determined. Before using the modeling program, the shape of the body and the size determination was very complicated, it took more time and tended to be mistaken. Technological development in this field has provided more reliable accounting methods capable of developing more accurate models in relatively fast deadlines. However, the exact modeling basis remains dependent on the quality of the data and the understanding and interpretation of the model. A variety of algorithms have been developed to construct such interpolations (Morrison, 1974), e.g., inverse distance weighting (IDW) (Kane et al., 1982). Interpolation is widely used for both predictive and visualization purposes in geospatial studies.

Choosing the interpolating method for body building is the first action we do. The most commonly used methods are classical methods. Classical or geostatistical methods (Blanchin and Chilès, 1993) have proved their efficiency when enough data points are known on a relatively simple interface. We base the creation of the copper body on its geometry. Its geometry is simple and ideal for creating a 3D model.

\section{Inverse distance weight interpolation method}

IDW-Continues to use the simple linear combination of the proof weight values to estimate the calculation of reserves. It calculates the volumes in the way they are calculated for spatial continuity and anisotropy.

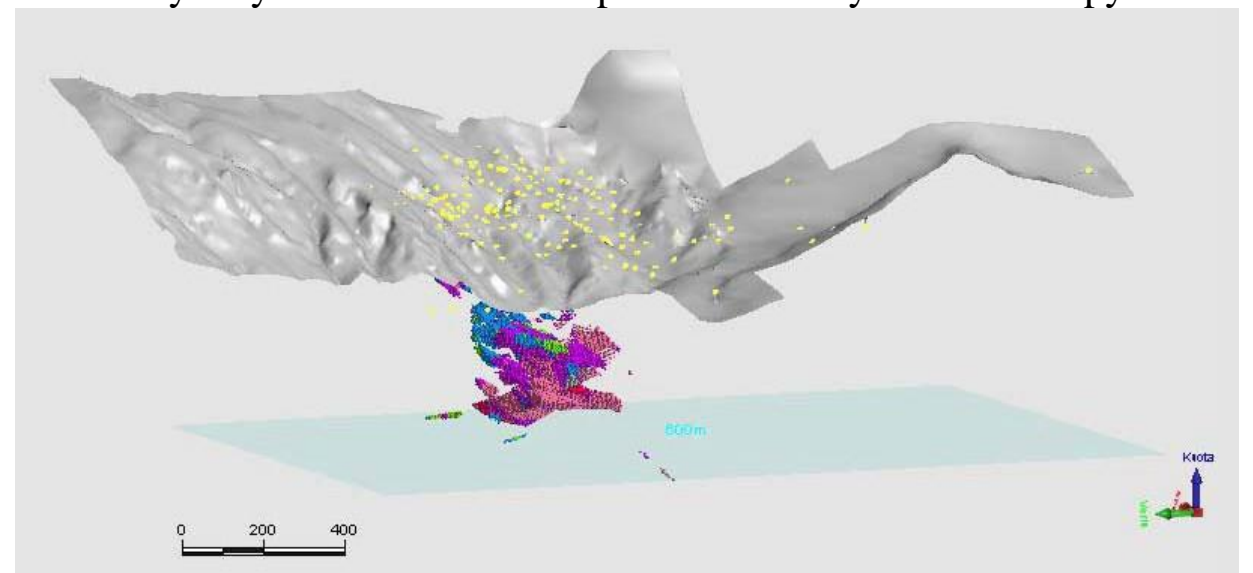

Figure 8. Division into blocks of copper bodies 


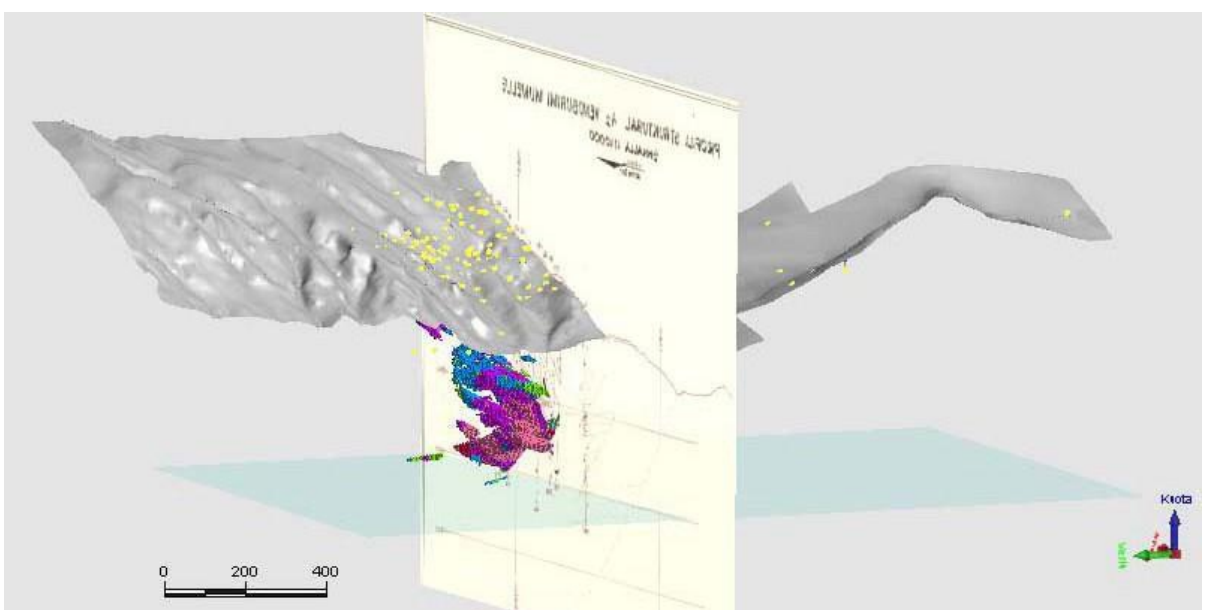

Figure 9. Division into blocks of copper bodies and their control by longitudinal section.

\section{Conclusion}

1. The 3D geological model for copper ore body, based on the methodology used and the results achieved was established;

2. From the analysis of classical statistics such as: histogram, cumulative frequency and probability. It turned out that for the element of copper, we have a normal distribution of data;

3. Based on the results of Histogram and cumulative frequency we can find the appropriate interpolation method for our ore bodies, for this case we can choose classical interpolation method or geostatistical interpolation methods. In this study is used only the Classical interpolation method (IDW); 4. An interrelation database of multiple information for mineralization in the study area (geology, geophysics, geochemistry, borehole, and crosssection data) was created;

5. The usage of implicit method of 3D modeling is very helpful for all new modeler and geologist;

6. This 3D model is applicable in metallic minerals deposits;

7. Resource estimation can be used to determine and define the ore tonnage and grade of a geological deposit, from the developed block model.

In terms of 3D modeling

$\checkmark \quad$ The same model can be used as a basis for calculating mineral reserves.

$\checkmark \quad$ With the wireframe module we managed to create copper ore bodies.

$\checkmark \quad$ They are powerful tools nowadays that help in a more accurate presentation of the built model.

$\checkmark \quad$ These programs offer quick processing and analyzing data

$\checkmark \quad$ Maintain information and provide real-time answers to different requirements. 


\section{References:}

1. Annels, A. E. 1991. Mineral Deposit Evaluation. A Practical. Approach. xv + 436pp.

2. Blanchin, R. \& Chilès, JP. Math Geol (1993) 25: 963. https://doi.org/10.1007/BF00891054

3. Calcagno, P., Chilès, J., Courrioux, G., Guillen, A., 2008. Geological modelling from field data and geological knowledge: Part I. Modelling method coupling $3 D$ potential-field interpolation and geological rules. Physics of the Earth and Planetary Interiors 171 (1e4), 147e157.

4. Fallara, F., Legault, M., Rabeau, O., 2006. 3-D integrated geological modeling in the Abitibi subprovince (Quebec, Canada): techniques and applications. Exploration and Mining Geology 15 (2), $27 \mathrm{e} 41$.

5. Gongwen Wang*, Lei Huang $3 D$ geological modeling for mineral resource assessment of the Tongshan $\mathrm{Cu}$ deposit, Heilongjiang Province, China , Geoscience Frontiers Volume 3, Issue 4, July 2012, Pages 483-491

6. Mallet, J.L., 2002. Geomodeling (Applied Geostatistics Series). Oxford University Press, New York, p. 624.

7. Morrison, J.L., 1974. Observed statistical trends in various interpolation algorithms useful for first stage interpolation. The Canadian Cartographer 11, 142e159.

8. R.Kamberaj, N. Bardhoshi

9. ."Mbi rezultatet e punimeve gjeologjike të kërkim zbulimit në vendburimin Munellë dhe llogaritja e rezervave me gjendje I.I.1980."

10. Wang, G., Chen, J., Du, Y., 2007. Three-dimensional localization prediction of deposit and mineralization environment quantitative assessment: a case study of porphyry copper deposits in Sanjiang region, China. In: Proceedings of IAMG, 07 Geomathematics and GIS Analysis of Resources, Environment and Hazards, Beijing, China, pp. $102 \mathrm{e} 105$. 